\title{
Research on Incentive Mechanism of Innovative Science and Technology Talents
}

\author{
Yuwei Zhao \\ Hebei University of Science and Technology \\ Shijiazhuang, China
}

\begin{abstract}
In today's world, the competition of comprehensive national strength is more and more reflected in the competition of science and technology, scientific and technological talents are increasingly becoming the decisive factor in the development of science and technology. With the acceleration of the process of economic globalization, talents, especially high-level innovative scientific and technological talents, have become a strategic resource and the object of competition among countries. Based on the analysis of the demand characteristics of innovative scientific and technological talents and the existing problems in the incentive of innovative scientific and technological talents, this paper puts forward some Suggestions on the construction of incentive mechanism of innovative scientific and technological talents.
\end{abstract}

Keywords-innovative scientific and technological talents; incentive mechanism; management mechanism

\section{INTRODUCTION}

The so-called "innovative talents" refers to those who have innovative consciousness, spirit and ability and can achieve innovative results. With the acceleration of economic globalization, the competition among economic organizations is more and more manifested as the competition of scientific and technological strength, and the ability of independent innovation of science and technology is the essential requirement of enhancing scientific and technological strength. General Secretary Xi Jinping pointed out that having a large number of innovative young talents is the vitality of national innovation and the hope of scientific and technological development. With the deep implementation of the strategy of strengthening the country, China attaches more importance to the introduction and cultivation of innovative scientific and technological talents, insists on the cohesion of talents with undertakings, cultivates talents with practice, actively creates a good environment, constructs innovative carriers and platforms, and supports scientific and technological talents to achieve their career in innovative scientific and technological activities. But at the present stage, the incentive mechanism for innovative scientific and technological talents in China is still relatively weak, and there are a series of problems. Because there are some deviations in the recognition of incentive mechanism, this will lead to many scientific and technological talents to reduce their enthusiasm for work, unable to give full play to their due creativity, and even lead to more and more scientific and technological talents outflow. Therefore, establishing an effective incentive mechanism for scientific and technological talents and stimulating the enthusiasm and creativity of scientific and technological talents is of great significance for strengthening the construction of China's scientific and technological talents.

\section{MaIn Demand CHARACTERISTICS OF INNOVATIVE SCIENCE AND TECHNOLOGY TALENTS}

\section{A. Material Needs}

Material demand is the inevitably lowest level of demand for innovative scientific and technological talents, and it is also a powerful driving force to promote their innovative behavior. In many people's view, material aspects such as salary are not only to meet the basic survival needs, but also symbolize the status, identity and power of employees in the organization, and reflect the self-worth of a person.

\section{B. Desire to Be Respected and Recognized}

Innovative science and technology talents pay more attention to the pursuit of autonomy, independence and innovation, eager to be recognized and respected, and eager to realize their own values. They tend to have an autonomous working environment and prefer challenging and creative work to repetitive work. By completing challenging and creative work, they can realize their self-value and gain recognition from colleagues, organizations and society.

\section{Paying Attention to Personal Career Development}

Innovative technology talents have the need to update their knowledge and continuously improve their own levels. Modern scientific and technological knowledge updates rapidly. Only by constantly learning new knowledge and tracking the cutting-edge scientific research in their field can scientific and technological talents actively carry out innovation activities and solve major technical problems for the organization. The organization should fully understand the individual learning needs and career development intentions of innovative scientific and technological talents, and provide them with a good learning environment and career development opportunities. 
technological talents. It is also necessary to link the salary income of scientific and technological talents with the performance of units to further stimulate the enthusiasm and creativity of scientific and technological talents. As for the bonus incentive mechanism, the bonus incentive is conducted for the talents who can effectively complete the organizational tasks, guarantee the work results and make outstanding contributions in various aspects, so as to stimulate the enthusiasm and creativity of scientific and technological talents to a greater extent. On the basis of the above incentive mechanism, a humanized welfare incentive system should be established. For example, scientific and technological talents can have paid vacation, and provide them with some free medical examinations and official subsidies. In addition, relevant units should also provide five insurance and one fund for scientific and technological talents, solve the problems of old-age pension and medical treatment for employees, and provide comprehensive welfare guarantee for scientific and technological talents.

\section{B. Affirmative Incentive}

Achieving affirmation of work results can make scientific and technological talents get a sense of achievement that material returns cannot bring. This way affirms the level, ability and contribution of scientific and technological talents, and is a celebration of their successful performance of their duties. Affirmative incentive can be carried out from three aspects: affirming the accomplishment of tasks, affirming scientific and technological progress and affirming innovative ideas.

Affirm the completion of tasks, focus on special tasks, timely affirm the efforts made by scientific and technological talents, and comprehensively summarize the achievements of scientific and technological talents in all aspects. Affirm scientific and technological progress, affirm the achievements of scientific and technological talents in the field of scientific and technological progress, make a good plan for award evaluation, and actively organizing awards such as the Science and Technology Progress Award. Affirm innovative thinking. For scientific and technological talents with strong innovative spirit, the organization should encourage and support them to affirm their innovative thinking and free exploration of science.

\section{EFFECTIVE CONSTRUCTION OF INCENTIVE MECHANISM FOR INNOVATIVE SCIENTIFIC AND TECHNOLOGICAL TALENTS}

\section{A. Material Incentive}

Material reward can not only improve the quality of life of scientific and technological talents, but also enable talents to gain social and cultural identity. Material incentive can be carried out from three aspects: salary incentive mechanism, bonus incentive mechanism and welfare incentive mechanism to provide more effective material guarantee for innovative scientific and technological talents.

The salary incentive mechanism needs to change the previous salary system which is mainly based on the post skill salary system, to realize a multi-mode salary system, and to more reflect the contribution of scientific and

\section{Cultural Incentive}

Good organizational culture can make scientific and technological talents have a sense of belonging and achievement. Through the shaping of organizational culture, it can achieve the effect of motivating organizational members. It is necessary to strengthen the cultural education of scientific and technological talents, implement the core values of "national interests first", adhere to the trend, always maintain the advanced nature, always carry forward the scientific spirit, always emphasize organizational discipline, and encourage scientific and technological talents to serve the motherland with fervent patriotism. 
ultimate incentive, mainly to link work performance with promotion, selection model, and evaluation, and to be calibrated in a certain form or name. Pursuing a good reputation is the need for the development of scientific and technological talents. Honor can constantly encourage the talents of science and technology to maintain and carry forward their achievements. It can also appeal to other people and stimulate competitive power, thus producing better incentive effects.

Within the organizational management talents, the superior management should respect the personality of the scientific and technological talents, respect the pioneering spirit, enterprising spirit and unique views of the scientific and technological talents. Trust scientific and technological talents and let them work boldly. When scientific and technological talents encounter difficulties, their superiors should actively support them to help scientific and technological talents solve problems and increase the sense of security and trust of scientific and technological talents. Help scientific and technical personnel to maintain the optimism of life and enhance the ability to withstand setbacks

\section{E. Target Motivation}

Target motivation is to motivate people's motivation and guide people's behavior through the setting of goals, so that the personal goals of science and technology talents are closely linked with organizational goals, in order to stimulate the enthusiasm, initiative and creativity of science and technology talents.

The goal is the expected result of action and the object of meeting people's needs. Appropriate setting goals can stimulate people's motivation and mobilize people's enthusiasm. The ultimate goal of scientific and technological talents and the ultimate goal of the enterprise must be consistent. Through setting goals to stimulate the motivation of scientific and technological talents, guide their behavior, and combine individual needs with technological goals, so as to stimulate the enthusiasm of scientific and technological talents and reimburse the motherland with greater enthusiasm to join the cause.

\section{F. Work Motivation}

Through scientific distribution of work, appropriate scientific and technological talents are arranged in appropriate positions and human resources are reasonably allocated to enable organizational members to realize their self-value as much as possible, so as to achieve the purpose of motivation. For scientific and technological talents who just step on the job, or technical backbones facing new challenges, they can quickly adapt to the work content and timely produce work results, which can bring great satisfaction and sense of achievement to scientific and technological talents.

\section{G. Honorary Incentives}

Honorary incentive makes an ultimate incentive means, which mainly links work achievement with promotion, model selection and advanced evaluation, and is calibrated in a certain form or name. Honorary incentives make an

\section{H. Environmental Incentives}

In addition to providing a quiet and harmonious office environment for scientific and technological talents, it is more important to continuously carry out technological transformation and technology introduction, add advanced scientific research equipment, provide academic exchanges, the Internet, public databases, books and other software facilities, so that scientific and technological talents can understand and master cutting-edge technical conditions.

\section{CONCLUSION}

Innovative scientific and technological talents are an important strategic resource of the country and an important force for the great rejuvenation of the Chinese nation and the realization of the "Chinese Dream". A scientific and rational incentive mechanism for scientific and technological personnel is conducive to fully mobilizing their enthusiasm, giving full play to their potential and enhancing the country's innovation capacity. Through the exploration and improvement of the incentive mechanism of innovative talents in China, this paper hopes to promote the healthy development of innovative scientific and technological talents.

\section{REFERENCES}

[1] Wang Jianxin, Ji Yangzhou. Strengthening the Construction of Innovative and Entrepreneurial Talent Team [J]. Personnel World, 2011.

[2] Zhou Xuejun, Hu Yuchen. Study on the Compound Effectiveness of Regional Science and Technology Talents, the Relationship between Science and Technology Investment and Talents Flow [J]. Science and Technology Progress and Countermeasures, 2013 (13): 146-149.

[3] Wujiang. On the Selection and Training of Innovative Science and Technology Talents in China [J]. Chinese Talents, 2010 (10). pp.

[4] Jiang Zheng, Jinxin. Cultivation and Encouragement of Innovative Talents in Small and Medium-sized Enterprises [J]. Enterprise Reform and Management, 2015 (7): 54-55.

[5] Guo Junliang. Strengthen the Cultivation of Scientific and Technological Talents to Enhance the Innovation Vitality of Enterprises [J]. Hebei Enterprises, 2015 (9): 103.

[6] Zhang Dong. An Analysis of the Incentive Mechanism for Science and Technology Talents in Small and Medium-sized Financial Institutions [J]. Taxation, 2018 (7): 217. 